\title{
Role of the CASP-9 Ex5+32 G>A polymorphism in susceptibility to cancer: A meta-analysis
}

\author{
SHI YAN, YONG-ZHI LI, XIN-WANG ZHU, CHUN-LAI LIU, PING WANG and YI-LI LIU \\ Department of Urological Surgery, The Fourth Affiliated Hospital of China Medical University, \\ Shenyang, Liaoning, P.R. China
}

Received May 27, 2012; Accepted August 28, 2012

DOI: $10.3892 /$ etm.2012.756

\begin{abstract}
Failure of apoptosis is one of the hallmarks of cancer. As an execution-phase caspase, caspase- 9 plays a crucial role during apoptosis. To examine whether the Ex5+32 $\mathrm{G}>\mathrm{A}$ (rs1052576) polymorphism in the CASP-9 gene alters cancer risk, we conducted a comprehensive meta-analysis of 7 case-control studies consisting of a total of 1668 cancer cases and 2294 healthy controls. All studies considered, A allele and A allele carriers of Ex $5+32 \mathrm{G}>\mathrm{A}$ in the CASP-9 gene had significant associations with cancer risk $(\mathrm{OR}=0.72$, 95\% CI, 0.58-0.89, $\mathrm{P}=0.003$; OR=0.76, 95\% CI, 0.63-0.92, $\mathrm{P}=0.004$; respectively). In the subgroup analysis, we found that the A allele of Ex5+32 G>A was a protective factor for cancer risk in Chinese and American populations ( $\mathrm{OR}=0.60$, 95\% CI, 0.44-0.81, P<0.001; OR=0.80, 95\% CI, 0.69-0.94, $\mathrm{P}=0.005$; respectively). Similarly, we also found positive associations between A allele carriers of Ex5+32 G>A and cancer risk in Chinese and American populations $(\mathrm{OR}=0.63$, 95\% CI, 0.44-0.90, $\mathrm{P}=0.01 ; \mathrm{OR}=0.78,95 \% \mathrm{CI}, 0.62-0.98$, $\mathrm{P}=0.03$; respectively). In addition, we identified that $\mathrm{A}$ allele and $A$ allele carriers of Ex $5+32 \mathrm{G}>\mathrm{A}$ may decrease the risk of cancer in the Asian population $(\mathrm{OR}=0.60,95 \%$ CI, 0.44-0.81, $\mathrm{P}<0.001 ; \mathrm{OR}=0.63,95 \% \mathrm{CI}, 0.44-0.90, \mathrm{P}=0.01$; respectively). In conclusion, this meta-analysis demonstrated that $\mathrm{A}$ allele and A allele carriers of the Ex $5+32 \mathrm{G}>\mathrm{A}$ polymorphism in the CASP-9 gene may be protective factors for cancer risk.
\end{abstract}

\section{Introduction}

Apoptosis is an essential mechanism to eliminate unwanted cells during the development and homeostasis of multicellular organisms $(1,2)$. An imbalance between cell death and proliferation may lead to the incidence of cancer. There are two main apoptotic pathways in humans, the extrinsic pathway and the intrinsic pathway (3). During the apoptotic process, both of the

Correspondence to: Professor Yi-Li Liu, Department of Urological Surgery, The Fourth Affiliated Hospital of China Medical University, Shenyang, Liaoning 110004, P.R. China

E-mail: cmu4h_lyl@126.com

Key words: caspase-9, polymorphism, cancer, meta-analysis two pathways use the caspase enzyme cascade; the extrinsic pathway utilizes caspases- 8 and -10 , while the intrinsic pathway employs caspase- 9 and the converge to use caspases-3, -6 and -7 as effector caspases, which lead to cell death by nuclear membrane breakdown, DNA fragmentation, chromatin condensation and the formation of apoptotic bodies (4-6).

Caspase-9, an apoptosis-related cysteine peptidase, encoded by the CASP-9 gene, located on chromosome 1 at $1 \mathrm{p} 36.21$, is a member of the caspase (cysteine aspartate protease) family of proteins. It has been shown to be an executioner protein of apoptosis. Caspase-9 plays a central role in the execution-phase of cell apoptosis. Single nucleotide polymorphisms (SNPs) are the most common form of human genetic variation and may contribute to an individual's susceptibility to cancer (7). In recent years, few studies have been performed to investigate the associations between effector caspases and cancer risk. Lan et al (8) found that CASP-9 was significantly associated with a decreased risk for non-Hodgkin lymphoma. Hosgood et al (9) found that individuals with the AG and AA genotypes of CASP-9 Ex 5+32 G>A experienced a decreased risk of multiple myeloma. However, we are still may unable to reach a consistent conclusion concerning the association between the CASP-9 Ex5+32 G>A (rs1052576) polymorphism and cancer risk according to previous studies. Therefore, we performed a Human Genome Epidemiology (HuGE) review and meta-analysis by including the most recent and relevant articles to identify statistical evidence.

\section{Materials and methods}

Literature search. We performed an electronic search of the PubMed, Cochrane library, Embase, Web of Science, SpringerLink, CNKI and CBM databases extensively to identify relevant studies available up to May 1, 2012. The search terms included ['caspase-9' or 'CASP-9' or 'caspase-9' (Mesh)] and ['SNPs' or 'SNP' or 'polymorphism, genetic' (Mesh)] and ['cancer' or 'tumor' or 'neoplasms' (Mesh)]. References in the eligible studies or textbooks were also reviewed through a manual search to identify other potentially eligible studies.

Inclusion and exclusion criteria. The included studies were required to meet the following criteria: i) case-control studies focusing on associations between the CASP-9 Ex5+32 polymorphism and cancer risk; ii) all patients were diagnosed with 


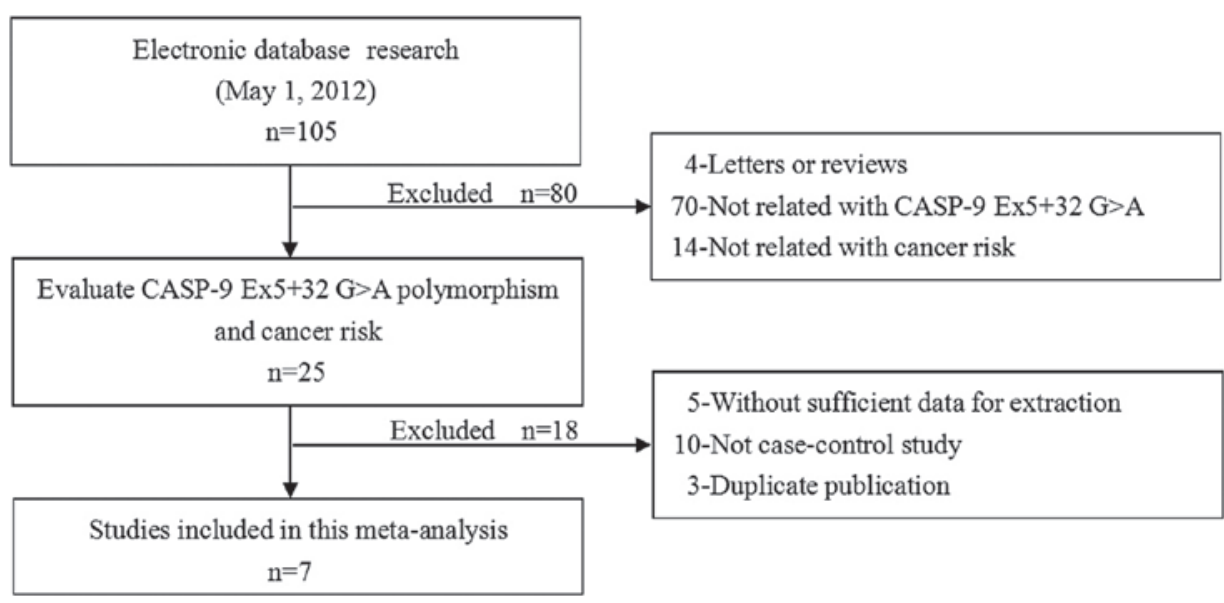

Figure 1. Flow chart shows study selection procedure. Seven case-control studies were included in this meta-analysis.

malignant tumors confirmed by pathological examination of the surgical specimen; iii) the frequencies of alleles or genotypes in case and control groups could be extracted; iv) the publication was in English or Chinese. Studies were excluded when they were: i) not case-control studies concerning CASP-9 Ex $5+32$ polymorphism and cancer risk; ii) based on incomplete data; iii) irrelevant or overlapping data were reported; iv) meta-analyses, letters, reviews or editorial articles.

Data extraction. Using a standardized form, data from published studies were extracted independently by two reviewers (S. Yan and Y.-Z. Li) to populate the necessary information. The following information was extracted from each of the articles: first author, year of publication, country, language, ethnicity, study design, source of cases and controls, number of cases and controls, mean age, sample, cancer type, genotype method, allele and genotype frequency, and evidence of Hardy-Weinberg equilibrium (HWE) in controls. In case of conflicting evaluations, an agreement was reached following a discussion with a third reviewer (Y.-L. Liu).

Quality assessment of included studies. Two reviewers (S. Yan and Y.-Z. Li) independently assessed the quality of papers according to modified STROBE quality score systems $(10,11)$. Forty assessment items related to the quality appraisal were used in this meta-analysis, scores ranging from 0 to 40 . Scores of 0-20, 20-30 and 30-40 were defined as low, moderate and high quality, respectively. Disagreement was resolved by discussion.

Statistical analysis. The odds ratio (OR) and 95\% confidence interval (95\% CI) were calculated using Review Manager Version 5.1.6 (provided by the Cochrane Collaboration, available at: http://ims.cochrane.org/revman/download) and STATA Version 12.0 (StataCorp, College Station, TX) softwares. Between-study variations and heterogeneities were estimated using Cochran's Q-statistic $(12,13)(\mathrm{P} \leq 0.05$ was considered to be a manifestation of statistically significant heterogeneity). We also quantified the effect of heterogeneity by using $\mathrm{I}^{2}$ test, which ranges from 0 to $100 \%$ and represents the proportion of inter-study variability that can be contributed to heterogeneity rather than by chance. When a significant $\mathrm{Q}$-test $(\mathrm{P} \leq 0.05)$ or
$\mathrm{I}^{2}>50 \%$ indicated that heterogeneity among studies existed, the random effects model was conducted for meta-analysis. Otherwise, the fixed effects model was used. To establish the effect of heterogeneity on the conclusions of the meta-analyses, subgroup analysis was carried out. We tested whether genotype frequencies of controls were in HWE using the $\chi^{2}$ test. Funnel plots are often used to detect publication bias. However, due to limitations caused by varied sample sizes and subjective reviews, Egger's linear regression test which measures funnel plot asymmetry using a natural logarithm scale of OR was used to evaluate the publication bias (14). When the P-value was $<0.1$, publication bias was considered significant. All the $\mathrm{P}$-values were two-sided. To ensure the reliability and the accuracy of the results, two reviewers (S. Yan and Y.-Z. Li) populated the data in the statistical software programs independently and obtained the same results.

\section{Results}

Characteristics of the included studies. According to the inclusion criteria, seven studies $(8,9,15-19)$ met the inclusion criteria and were subjected to further examination. The flow chart of the study selection is shown in Fig. 1. In total, 1668 cancer cases and 2294 healthy controls from seven studies were included in the pooled analysis. The publication year of involved studies ranged from 2007 to 2009 . Overall, there were six types of cancers studied, including gastric cancer, lymphoma, lung cancer, colon cancer, myeloma and liver cancer. One of these studies was conducted in Russia, two in USA and four studies in China. The HWE test was performed on the genotype distribution of the controls in all included studies; all were in HWE $(\mathrm{P}>0.05)$. All quality scores of the included studies were higher than 20 (moderate-high quality). The characteristics and methodological quality of the included studies are summarized in Table I. The genotype distributions of the CASP-9 Ex $5+32 \mathrm{G}>\mathrm{A}$ polymorphism in the case and control groups are presented in Table II.

Main results and subgroup analysis. A summary of the findings of the meta-analysis of the association between CASP-9 Ex $5+32 \mathrm{G}>\mathrm{A}$ polymorphism and cancer risk is provided in Table III. The meta-analysis results showed that the A allele 
Table I. Characteristics of the individual studies in this meta-analysis.

\begin{tabular}{|c|c|c|c|c|c|c|c|c|}
\hline \multirow[b]{2}{*}{ Author/(Ref.) } & \multirow[b]{2}{*}{ Year } & \multirow[b]{2}{*}{ Country } & \multicolumn{2}{|c|}{ Number } & \multirow[b]{2}{*}{ Sample } & \multirow[b]{2}{*}{ Genotype method } & \multirow[b]{2}{*}{ Cancer type } & \multirow[b]{2}{*}{ Quality score } \\
\hline & & & Case & Control & & & & \\
\hline Fang et al (15) & 2007 & China & 70 & 100 & Blood & PCR-RFLP & Gastric cancer & 23 \\
\hline Lan et al (8) & 2007 & USA & 461 & 535 & Blood & DNA sequencing & Lymphoma & 22 \\
\hline Lou et al (16) & 2007 & China & 81 & 100 & Blood & PCR-RFLP & Lung cancer & 24 \\
\hline He et al (17) & 2008 & China & 170 & 100 & Blood & PCR-RFLP & Colon cancer & 21 \\
\hline Hosgood et al (9) & 2008 & USA & 128 & 516 & Blood/Tissue & DNA sequencing & Myeloma & 22 \\
\hline Ulybina et al (18) & 2009 & Russia & 111 & 110 & Blood & AS-PCR & Lung cancer & 24 \\
\hline Wu et al (19) & 2009 & China & 647 & 833 & Blood & PCR-RFLP & Liver cancer & 28 \\
\hline
\end{tabular}

PCR, polymerase chain reaction; RFLP, restriction fragment length polymorphism.

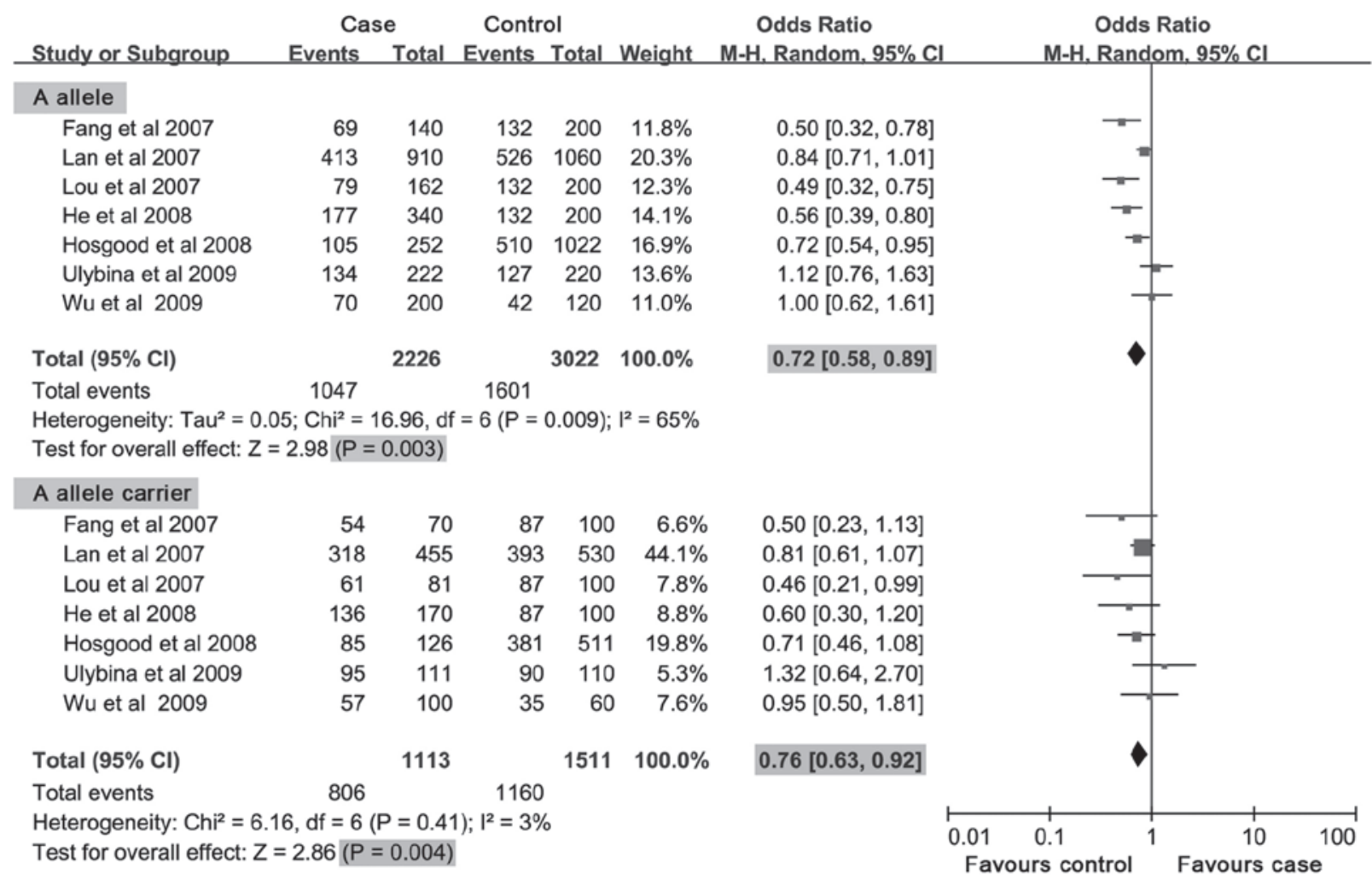

Figure 2. Associations between the CASP-9 Ex 5+32 G>A polymorphism and cancer risk.
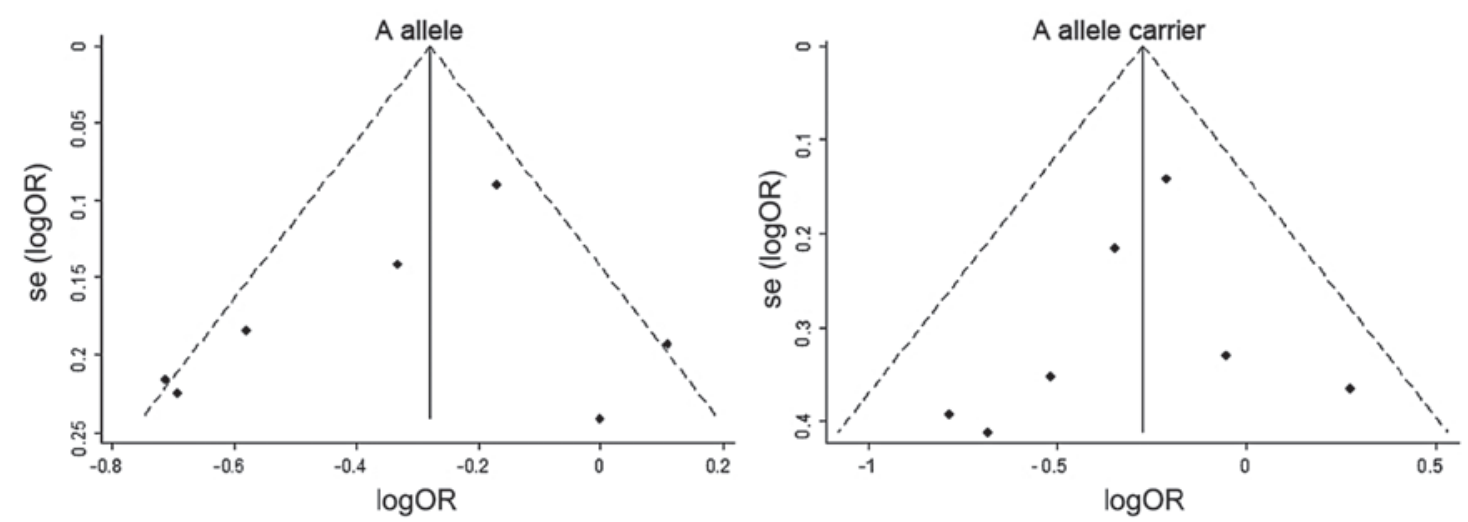

Figure 3. Begger's funnel plot of publication bias. 
and A allele carrier of Ex $5+32 \mathrm{G}>\mathrm{A}$ in the CASP-9 gene had negative associations with cancer risk $(\mathrm{OR}=0.72,95 \% \mathrm{CI}$, 0.58-0.89, P=0.003; OR=0.76, 95\% CI, 0.63-0.92, $\mathrm{P}=0.004$; respectively) (Fig. 2). In the subgroup analysis by country, we found that the A allele of Ex $5+32 \mathrm{G}>\mathrm{A}$ was a protective factor for cancer risk in Chinese and American populations $(\mathrm{OR}=0.60,95 \%$ CI, 0.44-0.81, $\mathrm{P}<0.001 ; \mathrm{OR}=0.80,95 \% \mathrm{CI}$, $0.69-0.94, \mathrm{P}=0.005$; respectively), but no association was found between the Ex5+32 G>A polymorphism with cancer risk in the Russian population. For the A allele carrier of the Ex $5+32$ $\mathrm{G}>\mathrm{A}$ polymorphism, we also found positive associations with cancer risk in Chinese and American populations $(\mathrm{OR}=0.63$, 95\% CI, 0.44-0.90, P=0.01; OR=0.78, 95\% CI, 0.62-0.98, $\mathrm{P}=0.03$; respectively). Unfortunately, there was no significant difference between the Ex $5+32 \mathrm{G}>\mathrm{A}$ polymorphism with cancer susceptibility in the Russian population. In the subgroup analysis by ethnicity, we found that the A allele and A allele carrier of Ex $5+32 \mathrm{G}>\mathrm{A}$ in CASP-9 might decrease the risk of cancer in the Asian population ( $\mathrm{OR}=0.60,95 \% \mathrm{CI}, 0.44-0.81$, $\mathrm{P}<0.001 ; \mathrm{OR}=0.63,95 \% \mathrm{CI}, 0.44-0.90, \mathrm{P}=0.01$; respectively). However, there were no associations found among A allele and A allele carrier of Ex $5+32 \mathrm{G}>\mathrm{A}$ in CASP-9 with risk in the Caucasian population (all $\mathrm{P}>0.05$ ).

Publication bias. Publication bias of the literature was assessed by Begger's funnel plot and Egger's linear regression test. Egger's linear regression test was used to measure the asymmetry of the funnel plot. All graphical funnel plots of the included studies appeared to be symmetrical (Fig. 3). Egger's test also showed that there was no statistical significance for all evaluations of publication bias (all $\mathrm{P}>0.05$ ).

\section{Discussion}

Apoptosis is a particular type of programmed cell death which commonly occurs in the developing embryo, in normal healthy adult tissues and in many pathological settings (20). The morphological features of apoptosis include changes in plasma membrane asymmetry and attachment, condensation of cytoplasm, nucleus and internucleosomal cleavage of DNA (21). However, excessive or failed apoptosis is a prominent morphological feature of several human diseases (24). Activation of caspases is of fundamental importance in cell death commitment and hence substantial efforts have been devoted to the understanding of mechanisms that underlie their activation $(22,23)$.

Caspase-9 is a key regulator of apoptosis or programmed cell death, an essential defense mechanism against hyper-proliferation and malignancy. Polymorphic variation in the CASP-9 gene has been reported to influence cancer risk, especially in the Ex $5+32$ variant. The published studies of an association between the CASP-9 Ex $5+32$ variant and different cancers have generated inconsistent results. Lou et al (16) reported that the rs1052576 which locates in exon 5 of the CASP-9 gene was associated with non-small cell lung cancer. However, a multi-center epidemiological case-control study was not consistent with other previously published data on non-Hodgkin lymphoma (8). This controversy might be due to population and ethnicity of the corresponding studies. In this meta-analysis, including a total of 1668 cancer cases and 2294 healthy controls from 
Table III. Meta-analysis of the association between the Ex $5+32 \mathrm{G}>\mathrm{A}$ polymorphism and cancer risk.

\begin{tabular}{|c|c|c|c|c|c|}
\hline Comparison & $\begin{array}{c}\text { Case } \\
\mathrm{n} / \mathrm{N}\end{array}$ & $\begin{array}{c}\text { Control } \\
\mathrm{n} / \mathrm{N}\end{array}$ & OR $(95 \% \mathrm{CI})$ & P-value & Effect model \\
\hline A allele & $1047 / 2226$ & $1601 / 3022$ & $0.72(0.58-0.89)$ & 0.003 & Random \\
\hline \multicolumn{6}{|c|}{ Subgroup analysis by country } \\
\hline Chinese & $395 / 842$ & $438 / 720$ & $0.60(0.44-0.81)$ & $<0.001$ & \\
\hline American & $518 / 1162$ & $1036 / 2082$ & $0.80(0.69-0.94)$ & 0.005 & \\
\hline Russian & $134 / 222$ & $127 / 220$ & $1.12(0.76-1.63)$ & 0.57 & \\
\hline \multicolumn{6}{|c|}{ Subgroup analysis by ethnicity } \\
\hline Caucasian & $652 / 1384$ & $1163 / 2302$ & $0.85(0.70-1.04)$ & 0.11 & \\
\hline Asian & $395 / 842$ & $438 / 720$ & $0.60(0.44-0.81)$ & $<0.001$ & \\
\hline A allele carrier & $806 / 1113$ & $1160 / 1511$ & $0.76(0.63-0.92)$ & 0.004 & Random \\
\hline \multicolumn{6}{|c|}{ Subgroup analysis by country } \\
\hline Chinese & $308 / 421$ & $296 / 360$ & $0.63(0.44-0.90)$ & 0.01 & \\
\hline American & $403 / 581$ & $774 / 1041$ & $0.78(0.62-0.98)$ & 0.03 & \\
\hline Russian & $95 / 111$ & $90 / 110$ & $1.32(0.64-2.70)$ & 0.45 & \\
\hline \multicolumn{6}{|c|}{ Subgroup analysis by ethnicity } \\
\hline Caucasian & $498 / 692$ & $864 / 1151$ & $0.82(0.66-1.02)$ & 0.08 & \\
\hline Asian & $308 / 421$ & $296 / 360$ & $0.63(0.44-0.90)$ & 0.01 & \\
\hline
\end{tabular}

seven independent studies, we examined the association of the Ex5+32 G>A polymorphism of the CASP-9 gene with cancer risk. We demonstrated that $\mathrm{A}$ allele and $\mathrm{A}$ allele carrier in the Ex5+32 G>A polymorphism had negative associations with cancer susceptibility, which showed a protective effect of the CASP-9 gene against cancer development. Ethnicity may influence cancer susceptibility by different genetic backgrounds and environmental exposures through gene-gene and gene-environmental interactions. Subgroup analysis showed that A allele and A allele carrier were protective factors for cancer risk in Chinese and American populations. Contrary to our expectations, we found no association between the Ex5+32 $\mathrm{G}>\mathrm{A}$ polymorphism and cancer risk in Russian population. In addition, we also identified that $\mathrm{A}$ allele and $\mathrm{A}$ allele carrier of Ex $5+32 \mathrm{G}>\mathrm{A}$ might decrease the risk of cancer in the Asian population, but not in the Caucasian population.

Similar to other meta-analyses, a number of limitations of this study should be addressed. First, the relevant research articles are not many and the sample size of this meta-analysis was not large. In addition, some relevant studies could not be included in our analysis due to incomplete raw data. Thirdly, we were not able to address the sources of heterogeneity among all studies. Fourthly, although all cases and controls of each study were well defined with similar inclusion criteria, there may be potential factors that were not taken into account that may have influenced our results. Most important of all, our meta-analysis was based on unadjusted OR estimates since not all published presented adjusted ORs or when they did, the ORs were not adjusted by the same potential confounders, such as ethnicity, gender and geographic distribution. Given these results, additional investigation in these areas is needed, and our conclusions should be interpreted cautiously.
In conclusion, this meta-analysis of seven case-control studies demonstrated that the CASP-9 Ex $5+32 \mathrm{G}>\mathrm{A}$ polymorphism is involved in the pathogenesis of variant cancer. The A allele, A allele carrier and AA genotype of Ex5+32 G>A polymorphism may be protective factors for cancer risk. As few studies are available in this field current evidence remains limited. Therefore, it is necessary to conduct large studies with adequate methodological quality, properly controlling confounds in order to obtain valid results.

\section{Acknowledgements}

We would like to thank Mr. J.L. Liu (MedChina Medical Information Service Co., Ltd.) for his valuable contribution and revision to the manuscript.

\section{References}

1. Raff M: Cell suicide for beginners. Nature 396: 119-122, 1998.

2. Jacobson MD, Weil M and Raff MC: Programmed cell death in animal development. Cell 88: 347-354, 1997.

3. Theodoropoulos GE, Gazouli M, Vaiopoulou A, Leandrou M, Nikouli S, Vassou E, Kouraklis G and Nikiteas N: Polymorphisms of caspase 8 and caspase 9 gene and colorectal cancer susceptibility and prognosis. Int J Colorectal Dis 26: 1113-1118, 2011.

4. Hajra KM and Liu JR: Apoptosome dysfunction in human cancer. Apoptosis 9: 691-704, 2004.

5. Nicholson DW and Thornberry NA: Caspases: killer proteases. Trends Biochem Sci 22: 299-306, 1997.

6. Kesarwani P, Mandal RK, Maheshwari R and Mittal RD: Influence of caspases 8 and 9 gene promoter polymorphism on prostate cancer susceptibility and early development of hormone refractory prostate cancer. BJU Int 107: 471-476, 2010.

7. Son JW, Kang HK, Chae MH, Choi JE, Park JM, Lee WK, Kim CH, Kim DS, Kam S, Kang YM and Park JY: Polymorphisms in the caspase- 8 gene and the risk of lung cancer. Cancer Genet Cytogenet 169: 121-127, 2006. 
8. Lan Q, Zheng T, Chanock S, Zhang Y, Shen M, Wang SS, Berndt SI, Zahm SH, Holford TR, Leaderer B, et al: Genetic variants in caspase genes and susceptibility to non-Hodgkin lymphoma. Carcinogenesis 28: 823-827, 2007.

9. Hosgood HD III, Baris D, Zhang Y, Zhu Y, Zheng T, Yeager M, Welch R, Zahm S, Chanock S, Rothman N and Lan Q: Caspase polymorphisms and genetic susceptibility to multiple myeloma. Hematol Oncol 26: 148-151, 2008.

10. von Elm E, Altman DG, Egger M, Pocock SJ, Gøtzsche PC and Vandenbroucke JP: STROBE Initiative: The Strengthening the Reporting of Observational Studies in Epidemiology (STROBE) statement: guidelines for reporting observational studies. Epidemiology 18: 800-804, 2007.

11. Zhang L, Liu JL, Zhang YJ and Wang H: Association between HLA-B*27 polymorphisms and ankylosing spondylitis in Han populations: a meta-analysis. Clin Exp Rheumatol 29: 285-292, 2011.

12. Higgins JP and Thompson SG: Quantifying heterogeneity in a meta-analysis. Stat Med 21: 1539-1558, 2002.

13. Zintzaras E and Ioannidis JP: Heterogeneity testing in metaanalysis of genome searches. Genet Epidemiol 28: 123-137, 2005

14. Peters JL, Sutton AJ, Jones DR, Abrams KR and Rushton L: Comparison of two methods to detect publication bias in metaanalysis. JAMA 295: 676-680, 2006.

15. Fang CQ, Liu SL, Lou Y and Li JH: Expression of the caspase 9 gene and its polymorphism distribution in gastric cancer. Shijie Huaren Xiaohua Zazhi 15: 3190-3193, 2007 (In Chinese).

16. Lou Y, Fang CQ and Li JH: A study on the expression of CASP9 gene and its polymorphism distribution in non-small cell lung cancer. Zhonghua Yi Xue Yi Chuan Xue Za Zhi 24: 59-62, 2007 (In Chinese).
17. He XM, Wang LL, Fang CQ, Liu SL, Lou Y and Li JH: Expression of CASP9 gene and its polymorphism distribution in colon cancer. Shijie Huaren Xiaohua Zazhi 16: 2371-2375, 2008 (In Chinese).

18. Ulybina YM, Kuligina ESh, Mitiushkina NV, Rozanov ME, Ivantsov AO, Ponomariova DN, Togo AV, Levchenko EV, Shutkin VA, Brenister SI, et al: Coding polymorphisms in Casp5, Casp8 and DR4 genes may play a role in predisposition to lung cancer. Cancer Lett 278: 183-191, 2009.

19. Wu H: Correlation between DNA pepair gene XRCC1 single nucleotide polymorphism and susceptibility to hepatocellular carcinoma in Fusui County of Guangxi. Guangxi Medical University, 2009

20. Alison MR and Sarraf CE: Apoptosis: a gene-directed programme of cell death. JR Coll Physicians Lond 26: 25-35, 1992.

21. Doonan F and Cotter TG: Morphological assessment of apoptosis Methods 44: 200-204, 2008.

22. Kumar S: Measurement of caspase activity in cells undergoing apoptosis. Methods Mol Biol 282: 19-30, 2004.

23. Kumar S and Dorstyn L: Analyzing caspase activation and caspase activity in apoptotic cells. Methods Mol Biol 559: 3-17, 2009.

24. Nicholson DW: ICE/CED3-like proteases as therapeutic targets for the control of inappropriate apoptosis. Nat Biotechnol 14: 297-301, 1996. 